\title{
Isolation of a microorganism capable of degrading poly-(L-lactide)
}

\author{
Yoko Ikura* and Toshiaki Kudo \\ Institute of Physical and Chemical Research ( RIKEN), Wako 351-0198, Japan
}

(Received February 1, 1999; Accepted October 19, 1999)

\begin{abstract}
The isolation of poly-(L-lactide) (PLA)-degrading microorganisms was investigated. A PLA-degrading actinomycete, strain No. 3118, was isolated and tentatively identified as a member of the genus Amycolatopsis. The optimum conditions for degradation of PLA were $43^{\circ} \mathrm{C}$ at about $\mathrm{pH} 7$ in a mineral salt medium with a low concentration of organic nutrients $(0.002 \%$ yeast extract). The original shape of PLA film (Mw $=2.3 \times 10^{5}$ after sterilization, $20 \mu \mathrm{m}$ thick) disappeared within 2 weeks. Lactic acid was detected after the film was incubated with culture supernatant.
\end{abstract}

Key Words_-Amycolatopsis; poly-(L-lactide) degradation; poly-(L-lactide)-degrading bacteria; poly-(L-lactide)-degrading conditions

Plastics are beneficial because of their facility, lightness, ease in processing, transparency, and low cost. Although some plastics are reused and recycled, the disposal of a large quantity of used plastic waste poses a great problem. Spacious land is required for burying waste material, and poisonous gas is often emitted when plastic waste is incinerated. Furthermore, abiotic plastics spoil the scenery and the ecological systems of many forms of life. Considering these problems, biodegradable plastics have been the subject of many research papers. Several kinds have been produced, such as poly ( $\beta$-hydroxybutyrate), polycaprolactone, and polyglycolic acid, and depolymerases capable of degrading these materials have been reported (Benedict et al., 1983; Chu, 1981; Kemnitzer et al., 1992; Reeve et al., 1994; Tanino et al., 1982). Poly-(L-lactide) (PLA), one of these biodegradable plastics, however, is expected to be used widely since its cost has decreased recently; already it is used in the medical field (Leenslag et al., 1987; Penning et al., 1993). PLA and other lactic acid-containing polymers are synthesized chemically (Dubois et al., 1991; Kricheldorf et al., 1992; Penning et al., 1993). Apart from its biodegradability, PLA has attracted attention as a material that can be made from renewable resources such as starch because lactic acid is produced through the fermentation of starch or glucose. It is completely harmless compared with abiotic polymers when used in vessels for edible products. PLA is known to degrade slowly in natural soil, but it

\footnotetext{
${ }^{*}$ Address reprint requests to: Dr. Yoko Ikura, Institute of Physical and Chemical Research (RIKEN), Wako 351-0198, Japan.
}

takes a long time for degradation to start. It can be hydrolyzed enzymatically (Ebeling et al., 1974; Fukuzaki et al., 1989; Reeve et al., 1994). Nevertheless, only a few reports have been made so far on the direct degradation of PLA by microorganisms.

One report concerns a mold capable of assimilating soluble PLA-oligomer and PLA-copolymer with glycerol (Torres et al., 1996). Furthermore, Pranamuda et al. (1997) reported the degradation of PLA by Amycolatopsis sp.

In the present study, we isolated a microorganism capable of efficiently degrading homo-PLA film in liquid culture. This strain differs from the one reported by Pranamuda et al. (1997), especially in terms of growth temperature and spore formation. In this report, we describe the identification of the PLA-degrading organism, the PLA-degradation conditions, and the products found in the culture supernatant.

\section{Materials and Methods}

Medium. A basal medium with the following composition was used (per liter): $\mathrm{K}_{2} \mathrm{HPO}_{4}, 1.55 \mathrm{~g}$; $\mathrm{NaH}_{2} \mathrm{PO}_{4} \cdot 2 \mathrm{H}_{2} \mathrm{O}, 0.85 \mathrm{~g} ;\left(\mathrm{NH}_{4}\right)_{2} \mathrm{SO}_{4}, 2.0 \mathrm{~g} ; \mathrm{MgCl}_{2}$. $6 \mathrm{H}_{2} \mathrm{O}, 0.1 \mathrm{~g} ; \mathrm{CaCl}_{2} \cdot 2 \mathrm{H}_{2} \mathrm{O}, 2 \mathrm{mg} ; \mathrm{FeSO}_{4} \cdot 7 \mathrm{H}_{2} \mathrm{O}, 2 \mathrm{mg}$; $\mathrm{Na}_{2} \mathrm{MoO}_{4} \cdot 2 \mathrm{H}_{2} \mathrm{O}, \quad 0.1 \mathrm{mg} ; \quad \mathrm{ZnSO}_{4} \cdot 7 \mathrm{H}_{2} \mathrm{O}, \quad 0.1 \mathrm{mg}$; $\mathrm{CuSO}_{4} \cdot 5 \mathrm{H}_{2} \mathrm{O}, 0.01 \mathrm{mg} ; \mathrm{CoCl}_{2} \cdot 6 \mathrm{H}_{2} \mathrm{O}, 0.02 \mathrm{mg} ; \mathrm{MnCl}_{2}$. $4 \mathrm{H}_{2} \mathrm{O}, 0.1 \mathrm{mg}$; yeast extract, $20 \mathrm{mg}$; agar (solid medium), $15 \mathrm{~g}$.

PLA film preparation. PLA $\left(\mathrm{Mw}=3.2 \times 10^{5}\right)$ from Shimadzu Co., Ltd. (Kyoto, Japan) consisting of 99.8\% L-lactic acid was used. PLA granules were dis- 
solved in chloroform at $2.0 \%(\mathrm{wt} / \mathrm{vol})$. The solution was poured into Petri dishes and dried. PLA film $20 \mu \mathrm{m}$ thick was prepared. Molecular weight after sterilization was $2.3 \times 10^{5}$, and no oligomer was found. These molecular weights were measured with GPC (Shimadzu Co., Ltd.).

Isolation. Soil supernatant, pond water or river water, was spread onto solid medium, and the plates were overlaid with PLA film. Colonies growing and appearing on the film were cultured in $10 \mathrm{ml}$ of liquid medium containing about $0.2 \% \mathrm{wt} / \mathrm{vol}$ PLA film at $30^{\circ} \mathrm{C}$ for 8 weeks. The strains that decreased the film weight by more than $5.5 \%$ were cultured again in the liquid medium at $30^{\circ} \mathrm{C}$ and $37^{\circ} \mathrm{C}$ for 4 weeks, and strains that efficiently decreased the film weight were isolated. Highly efficient PLA-degrading strains were obtained by repeated adaptation and selection procedures.

Identification of the strain. Czapek medium was used to grow the isolated microorganisms. Peptidoglycan type, mycolic acid, menaquinone, fatty acid pattern, and 16S rDNA sequence were analyzed by DSMZ (Deutche Sammlung von Mikroorganismen und Zellkulturen $\mathrm{GmbH}$, Germany). Other characteristics were investigated by the authors. The strain was classified according to DSMZ and Bergey's Manual of Determinative Bacteriology (Halt et al., 1993).

Measurement of film weight after cultivation. PLA film was taken out from the culture tubes, washed thoroughly with distilled water, and dried up overnight in a desiccator. All visible pieces of film were recovered.

Analyses of the products. Enzyme reaction with supernatant was carried out aseptically. Film was wiped with $70 \%$ ethyl alcohol and irradiated with UV light. Test tubes with sealed caps were autoclaved, and concentrated supernatant was filtrated with membrane filter $(0.22 \mu \mathrm{m}$ pore size, Millipore Co., Bedford, MA, USA). Formed lactic acid was measured with lactate dehydrogenase (Stolzenbach, 1966). Thin-layer chromatography was developed with a solvent system of the upper solution of $n$-butyl alcohol, acetic acid, and water $(4: 1: 5)$. Bromocresol Green was used as a colored indicator.

\section{Results and Discussion}

\section{Isolation and identification}

About 300 strains from 50 samples of soil, pond water and river water were isolated on plate culture and cultured in the liquid medium. After 8 weeks at $30^{\circ} \mathrm{C}$ under static conditions, 2 strains that decreased film weight by more than $50 \%$ were isolated. This shows that only a few microorganisms were capable of growth in liquid medium containing PLA film, al- though PLA-degrading microorganisms were often found on plate culture. Because these two isolates were found to be identical, only the results for strain No. 3118 are presented in Table 1. This strain showed the typical form of an actinomycete after 1 day of cultivation on a plate of Czapek medium, dividing into rods after 2 days of cultivation. The characteristics of strain No. 3118 were found to be consistent with those of members of the genus Amycolatopsis. The sequence of the first 500 bp of $16 \mathrm{~S}$ rDNA showed $96.9 \%$ similarity to that of $A$. mediterranei, indicating that strain No. 3118 is a new species of the genus Amycolatopsis because a similarity value of more than $99.4 \%$ is required to identify the species. Therefore we tentatively identified No. 3118 as a member of genus Amycolatopsis. This strain differs from the strain reported by Pranamuda et al. (1997) in the following characteristics. It was found to have spores and spore chains. This strain could grow at a temperature up to $48^{\circ} \mathrm{C}$, it could grow in the presence of $7 \% \mathrm{NaCl}$, and L-rhamnose is utilized. Because 16S rDNA sequence similarity was not described in the case of an Amycolatopsis reported by Pranamuda et al. (1997), we could not compare our strain with theirs (Pranamuda et al., 1997). However, it is clear that No. 3118 is different from the strain isolated by Pranamuda et al. (1997).

\section{Effects of temperature and nutrients on degradation of PLA}

The marked degradation of PLA on incubation at $43^{\circ} \mathrm{C}$ was seen at about $\mathrm{pH} 7$. In the practical use of this microorganism, conditions such as temperature and nutrient content of the medium will be important factors affecting the degradation. Yeast extract was employed as a nutrient. Because the strain grew within a wide range of temperatures (Table 1), degradation of PLA at various temperatures in the presence of yeast extract at various concentrations was investigated. As shown in Table 2, degradation occurred most rapidly at $43^{\circ} \mathrm{C}$ in the presence of $0.002 \%$ yeast extract, and PLA was degraded to some extent at temperatures below $37^{\circ} \mathrm{C}$. A very low concentration of yeast extract $(0.002 \%)$ stimulated the degradation of PLA, whereas a relatively high concentration (0.02\%) suppressed it. These findings were obtained after 11 days of cultivation, and a longer cultivation period might result in further degradation, even under relatively unfitting conditions.

\section{Time course of degradation}

The time course of the degradation of PLA is shown in Fig. 1 and a photograph is shown in Fig. 2. All visible pieces of film were recovered, although some found under a microscope were not gathered. Strain No. 3118 showed lower PLA-degrading activity at the 
Table 1. Identification of strain No. 3118.

\begin{tabular}{|c|c|c|c|}
\hline Aerial mycelium & + , white & Lactose & + \\
\hline Substrate mycelium & beige & D-Melibiose & $+/-$ \\
\hline Cell size & $0.5 \mu \mathrm{m}(1.5-7.5 \mu \mathrm{m}$ long, & D-Melezitose & - \\
\hline & after 2 days) & D-Trehalose & + \\
\hline Spore size & $0.8 \times 1.2 \mu \mathrm{m}$ & Raffinose & + \\
\hline Spore chains & + & Adonitol & - \\
\hline Flagella of vegetative cells & - & Inositol & + \\
\hline Flagella of spores & - & Mannitol & + \\
\hline Growth temperature $15^{\circ} \mathrm{C}$ & $+1-$ & meso-Erythritol & - \\
\hline $30^{\circ} \mathrm{C}$ & + & Salicin & + \\
\hline $48^{\circ} \mathrm{C}$ & + & Glycerol & + \\
\hline $53^{\circ} \mathrm{C}$ & - & Dextrin & + \\
\hline Gram stain & + & Starch & $+1-$ \\
\hline Growth in the presence of $7 \% \mathrm{NaCl}$ & + & Inulin & + \\
\hline Anaerobic growth & - & Decomnosition of & \\
\hline Catalase & + & & $+1-$ \\
\hline Oxidase & + & Xanthine & $\begin{array}{l}+1- \\
-\end{array}$ \\
\hline OF Test & no change & Benzoate & $\begin{array}{l}- \\
-\end{array}$ \\
\hline Hydrolysis of starch & + & $\begin{array}{l}\text { Derlzode } \\
\text { Citrate }\end{array}$ & + \\
\hline Hydrolysis of litmus milk & $+1-$ & citrate & + \\
\hline Hydrolysis of gelatin & + & Whole cell sugar & \\
\hline & & Arabinose & + \\
\hline Utilization of sugars & & Galactose & + \\
\hline D-Glucose & + & Diamino acid of peptidoglycan & DL-diaminopimelic acid \\
\hline D-Galactose & + & Mycolic acid & - \\
\hline L-Rhamnose & + & Menaquinone & MK-9 $\left(\mathrm{H}_{4}\right)$ \\
\hline D-Fructose & $+1-$ & Fatty acid pattern & branched saturated FA \\
\hline D-Ribose & - & & (16:0 iso), unsaturated FA \\
\hline L-Arabinose & $+/-$ & & (16:1 iso), 2-hydroxy FA \\
\hline D-Xylose & + & & $(16: 0$ iso $2 \mathrm{OH})$ and $10-$ \\
\hline Sucrose & + & & methyl branched FA $(17: 0$ \\
\hline Maltose & + & & 10-methyl), \\
\hline D-Cellobiose & + & 16 S rDNA sequence similarity ${ }^{a}$ & genus Amycolatopsis \\
\hline
\end{tabular}

a The first 500 bp sequence was analyzed.

Table 2. Effects of temperature and yeast extract on the degradation of PLA film.

\begin{tabular}{|c|c|c|c|c|}
\hline \multirow{2}{*}{$\begin{array}{c}\text { Yeast extract conc } \\
(\%)\end{array}$} & \multicolumn{4}{|c|}{ Loss of film weight (\%) } \\
\hline & $30^{\circ} \mathrm{C}$ & $37^{\circ} \mathrm{C}$ & $43^{\circ} \mathrm{C}$ & $48^{\circ} \mathrm{C}$ \\
\hline 0 & $9.2 \pm 0.7$ & $23.1 \pm 3.8$ & $58.2 \pm 5.9$ & $5.0 \pm 0.1$ \\
\hline 0.002 & $12.7 \pm 1.2$ & $53.1 \pm 4.3$ & $85.8 \pm 5.2$ & $12.5 \pm 3.4$ \\
\hline 0.02 & $6.7 \pm 0.5$ & $16.0 \pm 2.9$ & $49.6 \pm 3.6$ & $5.1 \pm 0.2$ \\
\hline
\end{tabular}

Weight loss was measured after 11 days of cultivation. The film weight loss was $3.1 \pm 0.4 \%$ after sterilization in the medium, and the film weight loss was $4.9 \pm 0.5 \%$ after 11 days of incubation at 30 to $48^{\circ} \mathrm{C}$ in the presence of yeast extract at various concentrations without inoculation (control values). Duplicate experiments were performed.

time when the organism was initially isolated; however, its activity increased as a result of repeated selection of the strain from cultures that showed high activity. The film was originally completely transparent. It became slightly opaque on sterilization in the medium, then whitened and rough during the cultivation period. The original shape of film disappeared within 2 weeks, accompanied by some bacterial growth $\left(\mathrm{OD}_{660}=0.27\right.$

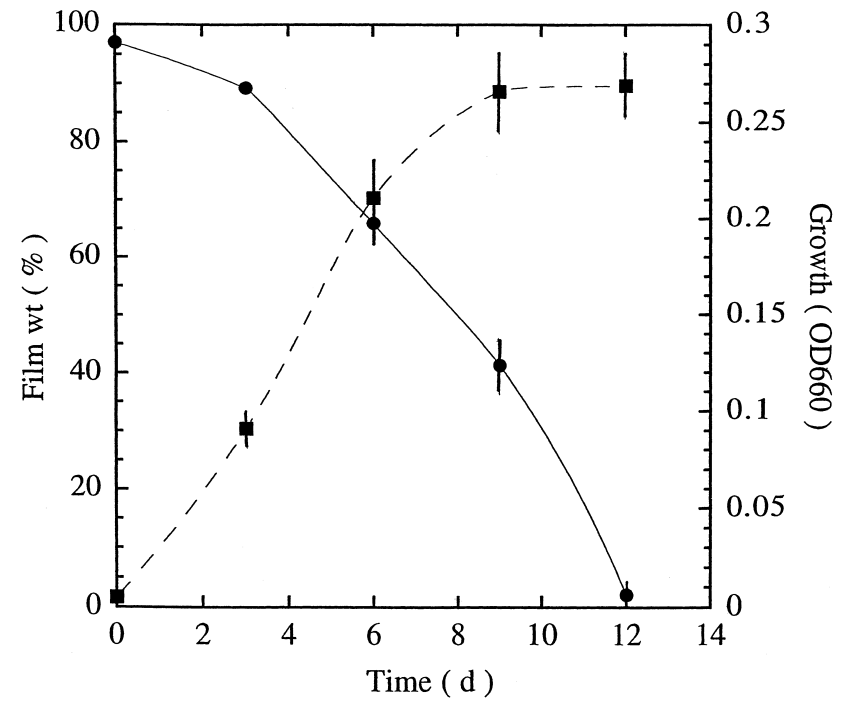

Fig. 1. Time course of degradation of PLA film at $43^{\circ} \mathrm{C}$.

The medium is described in the text. Cultivation was carried out at $\mathrm{pH} 7.0$ under static conditions after seeding $(1.0 \% \mathrm{vol} / \mathrm{vol})$ with a preculture. Symbols: $\bullet$, film wt; $\mathbf{\square}$, growth. Film weight before sterilization was calculated as $100 \%$, and the value at $0 \mathrm{~d}$ means weight after sterilization. The control value without inoculation was $94.9 \pm$ $0.3 \%$ after 12 days of incubation. Error bars show the standard error of the mean of four replicates. 


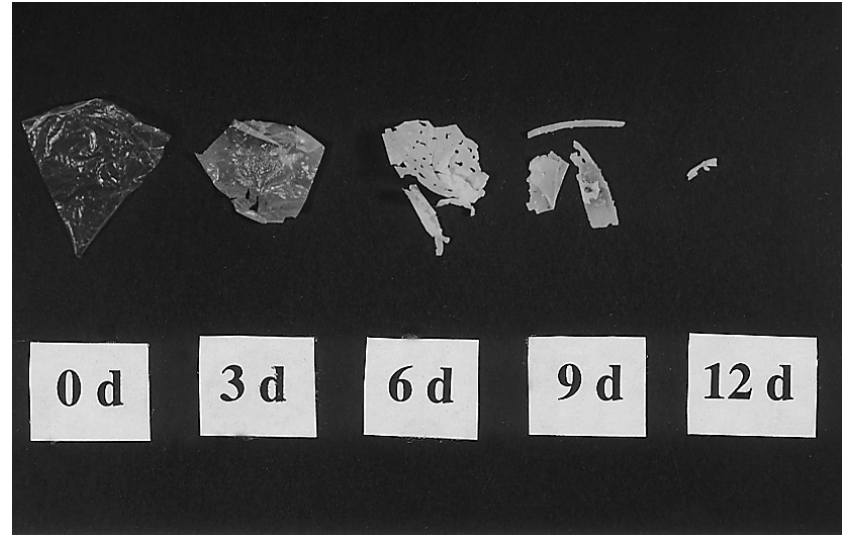

Fig. 2. Disintegration of PLA film during the culture.

The disintegration process typically observed on cultivation at $43^{\circ} \mathrm{C}$ is shown.

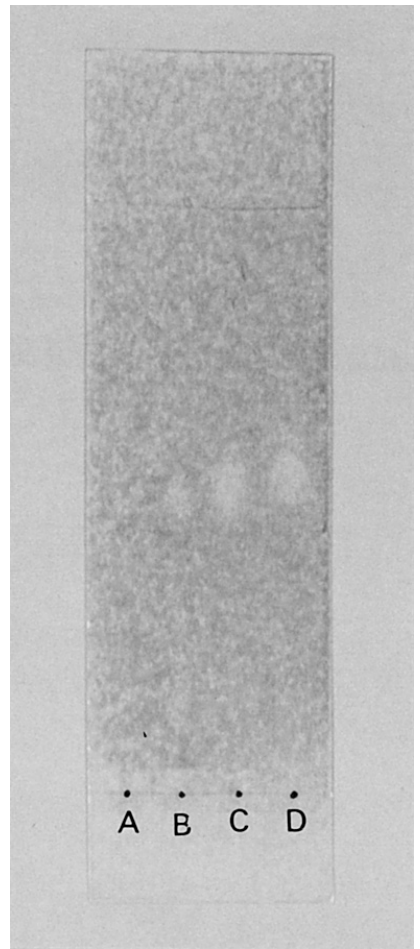

Fig. 3. Thin-layer chromatography after incubation of the supernatant with PLA film.

Culture supernatant (at $43^{\circ} \mathrm{C}$ for 12 days) was concentrated and incubated with film (1\%) at $43^{\circ} \mathrm{C}$ for 7 days. $\mathrm{A}$, incubation with heattreated supernatant $\left(100^{\circ} \mathrm{C}, 5 \mathrm{~min}\right)$; $\mathrm{B}$, incubation with supernatant; C, incubated supernatant (B) and lactic acid; D, lactic acid.

at maximum). On the contrary, maximum growth without film was 0.062 at $\mathrm{OD}_{660}$ (after 6 days), showing that the film was utilized as a carbon source. Reeve et al. (1994) reported that degradation of a polymer consisting of $100 \%$ L-type lactic acid by proteinase $\mathrm{K}$ is slower than in polymers containing $D$-type isomer at several ratios. Furthermore, the degradation of lactic acid-containing polymers occurs more rapidly than the degradation of homo-PLA. Since PLA, which was nearly $100 \%$ L-type, was used in our experiments, it seems likely that polylactic acids consisting of a certain percent of D-type isomers or other chemicals such as glycolic acid are presumably degraded easily and rapidly.

\section{Products in the culture supernatant}

The products generated from PLA film in the culture supernatant were analyzed. Cultivation was done with about $0.5 \%$ film. In the supernatant of 6 and 12 days cultivation, lactic acid was not detected by thin-layer chromatography or by the lactate dehydrogenase assay method. The supernatant was concentrated to about threefold, since protein in it was of low concentration $(0.05 \mathrm{mg} / \mathrm{ml})$. After incubation with film at $43^{\circ} \mathrm{C}$ for 7 days, lactic acid was detected (Fig. 3). Lactic acid produced was also confirmed by the lactate dehydrogenase assay method (Stolzenbach, 1966). This result indicates that the supernatant contained at least the degrading enzyme of an exotype hydrolase producing lactic acid. Finally, the strain certainly uses PLA as lactic acid.

We are grateful to Dr. Hideki Abe for measuring the molecular weights of PLA by GPC.

\section{References}

Benedict, C. V., Cook, W. J., Jarret, P., Camero, J. A., Huang, S. J., and Bell, J. (1983) Fungal degradation of polycaprolactones. J. Appl. Polym. Sci., 28, 327-334.

Chu, C. C. (1981) Hydrolytic degradation of polyglycolic acid. Tensile strength and crystallinity study. J. Appl. Polym. Sci., 26, 1727-1734.

Dubois, P., Jacobs, C., Jerome, R., and Teyssie, P. (1991) Macromolecular engineering of polylactones and polylactides. Macromolecules, 24, 2266-2270.

Ebeling, W., Hennrich, N., Klockow, M., Metz, H., Orth, H. D., and Lang, H. (1974) Proteinase K from Tritirachium album limber. Eur. J. Biochem., 47, 91-97.

Fukuzaki, H., Yoshida, M., Asano, M., and Kumakura, M. (1989) Synthesis of copoly(D,L-lactic acid) with relatively low molecular weight and in vivo degradation. Eur. Polym. J., 25, 1019-1026.

Halt, J. G., Krieg, N. R., Sneath, P. H. A., Stanley, J. T., and Williams, S. T. (1993) Bergey's Manual of Determinative Bacteriology, 9th ed., Williams and Wilkins, Baltimore, pp. 23442467.

Kemnitzer, J. E., McCarthy, S. P., and Gross, R. A. (1992) Poly( $\beta$ hydroxybutyrate) steroisomers $A$ model study of the effects of stereochemical and morphological variables on polymer biological degradability. Macromolecules, 25, 5927-5934.

Kricheldorf, H. R., Boettcher, C., and Tonnes, K. (1992) Polylactones 23. Polymerization of racemic and meso D,L-lactide with various organotin catalysts-Stereochemical aspects. Polymer, 33, 2817-2824.

Leenslag, J. W., Pennings, A. J., Bos, R. R. M., Rozema, F. R., and Boering, G. (1987) Resoursable materials of poly(L-lactide). Biomaterials, 8, 311-314.

Penning, J. P., Dijkstra, H., and Pennings, A. J. (1993) Preparation 
and properties of absorbable fibres from L-lactide copolymers. Polymer, 34, 942-951.

Pranamuda, H., Tokiwa, Y., and Tanaka, H. (1997) Polylactide degradation by an Amycolatopsis sp. Appl. Environ. Microbiol., 63, 1637-1640.

Reeve, M. S., McCarthy, S. P., Downey, M. J., and Gross, R. A. (1994) Polylactide stereochemistry: Effect on enzymatic degradability. Macromolecules, 27, 825-831.

Stolzenbach, F. (1966) Method in Enzymology 9, ed. by Wood, W.
A., Academic Press, New York, pp. 278-288.

Tanino, T., Fukui, T., Shirakura, Y., Saito, T., Tomita, K., Kaiho, T., and Masamune, S. (1982) An extracellular poly(3-hydroxybutyrate) depolymerase from Alcaligenes faecalis. Eur. J. Biochem., 124, 71-77.

Torres, A., Li, S. M., Roussos, S., and Vert, M. (1996) Screening of microorganisms for biodegradation of poly (lactic acid) and lactic acid-containing polymers. Appl. Environ. Microbiol., 62, 2393-2397. 